\title{
UNCERTAINTY IN VEHICLE COLLISION MODELING - SELECTED PROBLEMS
}

\author{
Aleksandrowicz P.*, Aleksandrowicz I. **
}

\begin{abstract}
Road accidents which cause personal and material losses are inseparably connected with development of motorization. Currently, experts who provide assessment of vehicle accidents use simulation programs. The results of the assessments have an impact on legal procedures in court cases. However, experts are often unaware of simplifications in modeling and the possibility of comparing simulation results with the use of different models. In this work, problems connected with generation of different results for the same event by a program are discussed. The results can be used by researchers, program designers and experts in practice.
\end{abstract}

\section{Keywords: Collision modeling, Crash model, Uncertainty in vehicle collision, SDC method, V-SIM.}

\section{Introduction}

These days are characterized by dynamic economic development of countries. This is possible, among others, due to efficient transport of goods and people in town agglomerations as well as outside them. An increase in peoples' mobility and transport of goods with the use of motor vehicles poses numerous threats. Experiences of the European Union state members confirm that development of motorization causes serious social-economic problems. Motorization index in Poland is systematically growing from year to year. In 2009 in Poland there were 22024697 registered motor vehicles, whereas in 2018, the number increased to 29656 238. Location of Poland in Europe and its situation within a transport trail from the East to the West generates high transit traffic. 12435345 vehicles entered Poland from abroad in 2018. Traffic volume and an increasing number of vehicles in Poland have a negative impact on the road traffic safety. In 2018, 31674 accidents were reported to the police in which 2862 people were killed, as compared to 2017 when 2831 people were killed, indicates an increase by $1.1 \%$. In road accidents as many as 37359 people were injured (http://statystyka.policja.pl). Determination of a driver at fault has not always been easy for the police. Special knowledge is required in doubtful cases or in complicated ones. Then, specialists in the field of road traffic accidents are appointed. Reconstruction of an accident is a process which is supposed to provide a creative solution to a problem with many unknows. This involves searching for dependencies between provided information, facts and parameters characterizing the circumstances of a given accident. Nowadays analyses of road accidents employ mainly calculation methods instead of an analytical approach which is rarely used. Different approaches to collision modeling and practical applications are presented, among others, in work (Kisilowski et al., 2016). The most advanced programs used for analysis of accidents are computer tools for modeling using the Finite Elements Method (FEM). They are usually used in research institutes and technical universities. For example, work (Cichański et al., 2015) includes results of numerical tests carried out in LS-Dyna environment. The simulation results were validated in experimental tests which involved crash tests performed on a full dimensional support structure of road infrastructure. Good consistence of simulation results with experimental results was obtained. Programs for modeling in FEM convention offer high calculation precision but in the practice of road accident reconstruction they are not commonly used. This results mainly from a long time needed to perform the calculations, computer capacity, input data to be used, and the fact that availability of ready numerical models is limited. However, reconstruction of an accident with the use of a simulation program is a labor-consuming, iterative process whose results need

\footnotetext{
* Piotr Aleksandrowicz, PhD.: Machine Maintenance Department, University of Science and Technology, Al. prof. S. Kaliskiego 7; 85 796, Bydgoszcz; Poland, p.aleksandrowicz@utp.edu.pl

** Iwo Aleksandrowicz, MSc.: Almot-Ekspert, Technical Department, J. Kusocińskiego 1, 86-032 Niemcz, Poland
} 
to be made available to the operator in a real time. Therefore, numerical analyses have dominated accident simulation programs with the use of MBS (Multi Body System) methods. Modeling in MBS convention is, however, simplified as compared to FEM. An expert is required to change many parameters and needs to be familiar with the software and the models to be used. In works (Kostek et al., 2017; Kostek et al., 2019) the authors present both the results of computer simulations of a car crash with a rigid obstacle obtained with a simulation program as well as the experimental results. The results were obtained for the same initial conditions, which enabled assessment of the computer simulation reliability and identification of selected parameters. After changing the identified parameters, it was possible to achieve a significantly better consistence of simulation results with the test results in relation to the program default data. The remaining difference is the result of a simplified modeling of forces that occur during the vehicle collision. Hence, it applies to the problem of modeling uncertainty and post collision movement of the vehicle. It appears whenever models of the same physical phenomenon provide different results. This problem is described in work (Wach et al., 2006), whose authors use Monte Carlo research method. Thus, experts should use a certain range of parameters for which they obtain similar accident circumstances, instead of a single simulation. It is caused by uncertainty of the accepted data and sensitivity of the accident simulation to the accepted input data. The most frequently used simulation programs for modeling collisions by MBS include: V-SIM4, PC Crash, Virtual Crash. V-SIM4 enables simulation of movement and collisions of a random number of vehicles according to the rules of dynamics in a nonhomogeneous environment. The program provides a database of vehicles and has a clearly designed work environment with an extended graphic edition modulus. For example, works (Aleksandrowicz, 2018a, b) present application of this program in movement analysis of a vehicle with braking system defects and different wear of its elements, while in (Porteš et al., 2017; Kučera et al., 2017; Kučera et al., 2019) the issues were discussed autonomous control lock of the differential in a truck. V-SIM4 can also be used to verify collisions using the SDC method, as discussed in the work (Aleksandrowicz, 2017). PC Crash also allows to simulate movement dynamics and vehicle impacts. Work (Dima et al., 2014) shows reconstruction of a passenger car collision with a truck using this program and the consistence of results was satisfactory. In turn, work (Coufal et al., 2014) provides a comparison and simulation of accident circumstances with the results provided with the use of Virtual Crash for a small overlap. The authors obtained satisfactory consistence of the simulation with the test results.

\section{Research tools and methods}

V-SIM4 program which is commonly used in Poland by expert witnesses and independent assessors was applied in the analysis. A 2D and 3D contact detection models were employed. The first one provides the possibility of contact detection by finding common parts of the object silhouette projections onto a perpendicular plane - surface. In the second one the impact is detected on the basis of the vehicle block common part volume permeation. V-SIM4 program offers two reference systems the first of which being used for a description of the simulated vehicle momentary position, designed elements of the movement environment and elements of the infrastructure. Location of this global reference system is established by the operator. In the second reference system which is connected with the simulated vehicle, external forces acting on the simulated object are determined and its center is determined by radius vector $r_{c}$ which is demonstrated in Fig. 1a.
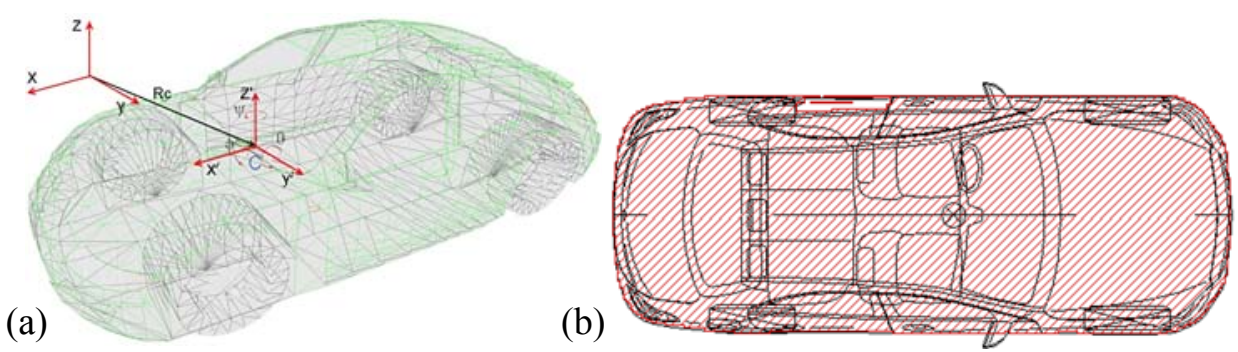

Fig. 1: Reference systems in the vehicle model (a) and body car rigid area preview (b).

The vehicle movement in V-SIM4 program is described in a 3D space and the model has three freedom degrees. V-SIM4 program offers two tire models, namely the TMeasy tire model and the Highway Safety Research Institute (HRSI) model. The vehicle model takes into consideration a kinematic model of an independent wheel suspension and the suspension rigidity as well as the steering system acting according 
to Ackerman's rule. The program also enables modeling of the wheel movement resistance increase caused by the body deformations and a punctured tire. They need, though, to be introduced by the operator who can use the impact force model in which the occurring forces develop in a constant manner throughout the contact of the simulated objects or a classic - impulse manner (Kudlih - Slibar), in which an exchange of force impulses between the objects takes place in a selected time. In the program the vehicle is treated as a block with single mass and averaged rigidity whose characteristic is close to linear (Bułka, 2016).

\section{Research object and impact parameters}

In order to carry out simulation calculations a scenario was accepted in which a passenger car hits a rigid barrier at the speed of $64 \mathrm{~km} \cdot \mathrm{h}^{-1}$ with $40 \%$ overlap, on dry, concrete surface, that is, consistently with the crash test. The research object was a passenger car Mercedes Benz W205. The most important technical data of the vehicle accepted for simulation calculations is presented in Tab. 1. The impact was analyzed with the use of a 2D detection model which is shown in Fig. $1 \mathrm{~b}$ for impulse and alternatively force model.

Tab. 1: Technical data of the research object.

\begin{tabular}{|c|c|}
\hline Parameter & Value \\
\hline Vehicle curb weight & $1430 \mathrm{~kg}$ \\
\hline Driver's weight & $75 \mathrm{~kg}$ \\
\hline Vehicle length / width & $4.686 \mathrm{~m} / 1.810 \mathrm{~m} / 1.442 \mathrm{~m}$ \\
\hline Vehicle wheelbase & $2.840 \mathrm{~m}$ \\
\hline Body rigidity coefficient & $701 \mathrm{kN} . \mathrm{m}^{-3}$ \\
\hline Inertia moments in $\mathrm{x}, \mathrm{y}, \mathrm{z}$ system & $566 / 2523 / 2677 \mathrm{~kg} . \mathrm{m}^{2}$ \\
\hline Tires & $205 / 60 \mathrm{R} 1692$ \\
\hline
\end{tabular}

\section{Case study - own research}

A simulation of an impact of a vehicle with an barrier was carried out in an impulse and force models with the use of the Mercedes vector silhouette. This silhouette represents a precise shape of the vehicle body thanks to which it can be successfully used in the accepted 2D collision detection model and the program accurately records the beginning of the vehicle body contact with an obstacle. Fig. 2a shows the designed impact scene and the vehicle in its initial position $t=0 \mathrm{~ms}$. Fig. $2 \mathrm{~b}$ and Fig. $2 \mathrm{c}$ show the test run and differences in the end position of the vehicles. Simulations were carred out in variants until the vehicle was stopped. Therefore, the time of their ending was different. Both simulation calculation variants took into consideration seizure of the vehicle front left wheel caused by hitting an rigid barrier.
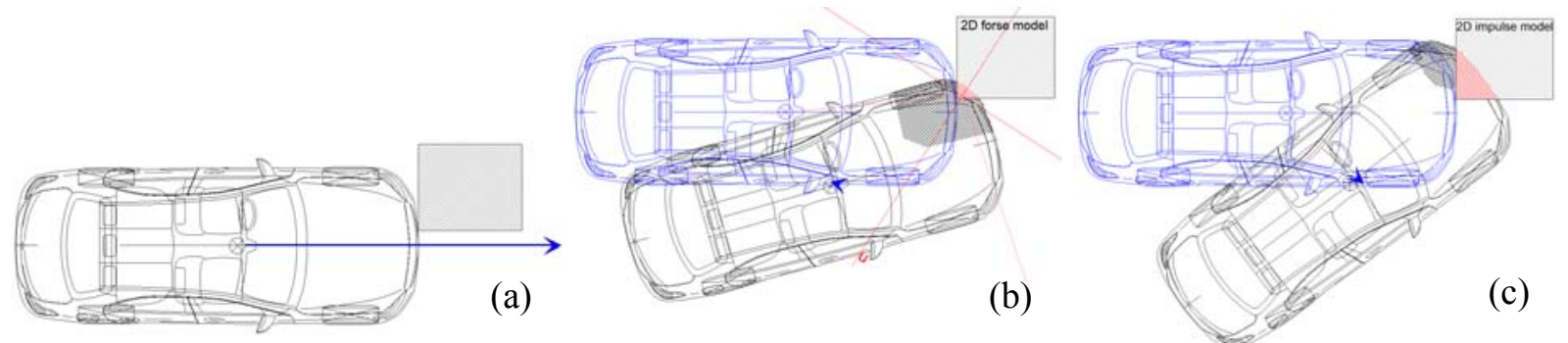

Fig. 2: View of the impact scene for $t=0 \mathrm{~ms}(\mathrm{a})$; force impact - end position of Mercedes in $t=1.024 \mathrm{~s}(\mathrm{~b})$ and impulse impact - end position of Mercedes in $t=1.505 \mathrm{~s}(\mathrm{c})$.

In Fig. 3a and Fig. 3b there are time courses of speed changes, distance covered, Mercedes rotation angle for both cases. 


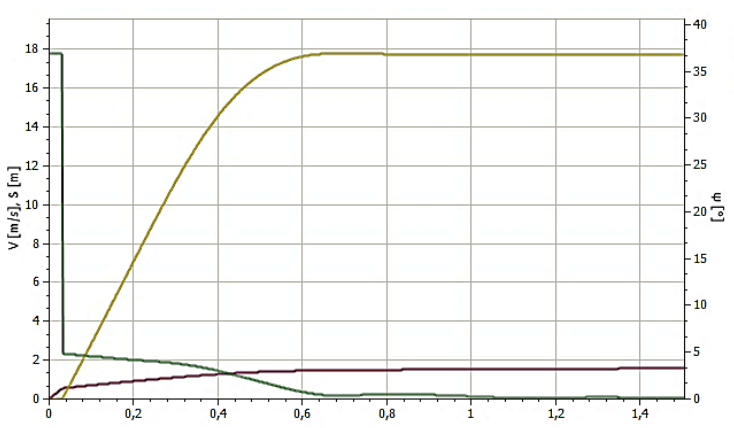

(a)

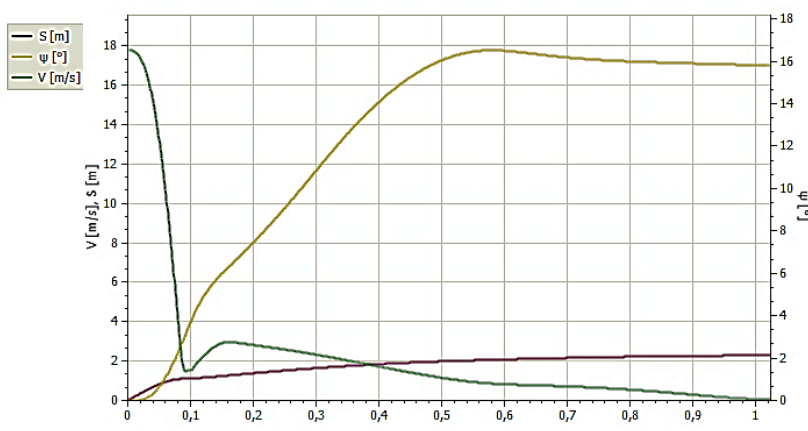

(b)

Fig. 3: Changes in V, S, $\Psi$ values for the impulse model (a) and force model (b).

\section{Conclusions}

The tests results have shown the following:

$>$ Simulation run of the same collision with an obstacle is different depending on the accident model, whereas the biggest differences have been observed for the body rotation angle $\Psi$ and for speed changes $V$ during the impact and the post impact movement,

$>$ Experts should take advantage of available models provided by a simulation program in which it is possible to obtain a similar course of events, instead of using only a single simulation considering its results to be the only and the most reliable ones.

\section{References}

Aleksandrowicz, P. (2018a) The impact of a vehicle braking system state on safe driving - part one, in: Proc. $17^{\text {th }}$ International Conference Diagnostic of Machines and Vehicles 2018, Pieczyska, Poland, doi:10.1051/matecconf/201818201025.

Aleksandrowicz, P. (2018b) The impact of a vehicle braking system state on safe driving - part two, in: Proc. $10^{\text {th }}$ International Scientific Session Applied Mechanics, Bydgoszcz, Poland, doi:10.1063/1.5091862.

Aleksandrowicz, P. (2017) Verifying a truck collision applying the SDC method, in: Proc. 58 ${ }^{\text {th }}$ International Conference of Machine Design Departments 2017, Praque, Czech Republic, pp. 14-19.

Bułka, D. (2016) V-SIM4 - User manual, CIBID Cracow (in Polish).

Cichański, A. and Stopel, M. (2015) Experimental Validation of the Numerical Model of a Testing Platform Impact on a Road Mast, Solid State Phenomen 224: 222-25, doi:10.4028/www.scientific.net/SSP.224.222.

Coufal, T. and Semeia, M. (2014) Research of impact parameters for traffic accident analysis in case of small overlap crash test, in: Proc. $2^{\text {nd }}$ Annual International Conference on Forensic Science - Criminalistics Research (FSCR), Singapore, pp. 1-9.

Dima D. S., Covaciu, D. and Chiru, A. (2014) Validation of simulation and optimization reconstruction in PC Crash with video recorded sample, in: Proc. $3^{\text {rd }}$ International Congress Science and Management of Automotive and Transportation Engineering 2014 Craiova, Romania, SMAT Paper no 2014-MTSRT51, pp. 207-212.

Kisilowski, J. and Zalewski, J. (2016) Modeling of collisions in road traffic, Scientific Publisher of the Institute of Sustainable Technologies - PIB Radom, pp. 30-104 (in Polish).

Kostek, R. and Aleksandrowicz, P. (2017) Simulation of car collision with an impact block, in: Proc. $11^{\text {th }}$ International Congress of Automotive and Transport Engineering 2017, Pitesti, Romania, IOP 012008, pp. 1-6, doi:10.1088/1757-899X/252/1/012008.

Kostek, R. and Aleksandrowicz, P. (2019) Study of vehicle crashes into a rigid barrier, Transactions of the Canadian Society for Mechanical Engineering, doi:10.1139/tcsme-2018-0057.

Porteš, P., Kučera, P., Pištěk, V., Fojtášek, J. and Zháňal, L. (2017) Modern tools for vehicle development in: Proc. $23^{\text {rd }}$ International Conference Engineering Mechanics 2017 Svratka, Czech Republic, pp. 54-57.

Kučera, P. and Pištěk, V. (2019) Prototyping a system for truck differential lock control, SENSORS, vol. 19, iss. 16, pp. 1-18, doi: 10.3390 / s19163619.

Kučera, P. and Pištěk, V. (2017) Testing of the mechatronic robotic system of the differential lock control on a truck, International Journal of Advanced Robotic Systems, vol. 14, iss. 5, pp. 1-7, doi. org/10.1177/172988 1417736897.

Wach, W. and Unarski, J. (2006) Uncertainty of calculation results in vehicle collision analysis, Forensic Science International, vol. 167, iss. 2-3, pp. 181-188. 